\title{
Intracerebroventricular Drug Administration in Pigeons ${ }^{1}$
}

\author{
CHARLES P. FRANCE, $²$ JILL U. ADAMS AND JAMES H. WOODS \\ Departments of Psychology and Pharmacology, University of Michigan, Ann Arbor, MI 48109
}

Received 15 February 1985

\begin{abstract}
FRANCE, C. P., J. U. ADAMS AND J. H. WOODS. Intracerebroventricular drug administration in pigeons. PHARMACOL BIOCHEM BEHAV 23(5) 731-736, 1985.-For many procedures used in behavioral pharmacology, the intracerebroventricular (ICV) route of drug administration is infrequently used due, in part, to the lack of a reliable technique for determining cannula patency in vivo. This study describes an in vivo technique for assessing ICV cannula patency in pigeons. The technique was applied in an experiment designed to evaluate several drugs, which are presumed to differ in the extent to which they enter the central nervous system, for their rate-suppressing effects in pigeons trained to peck a key on a fixed-ratio 20 schedule of food reinforcement. The opioid agonist morphine and antagonist quaternary naltrexone were 100 and 280 times more potent, respectively, in suppressing responding when administered ICV, as compared to systemic administration. Tertiary naltrexone was approximately equipotent as an antagonist of morphine's rate-suppressing effects when administered ICV or systemically. Quaternary naltrexone did not antagonize morphine by either route of administration. The utility of this in vive cannula verification technique is discussed, as well as the limitations of comparisons between systemically-administered tertiary and quaternary derivatives.
\end{abstract}

Morphine Naltrexone Quaternary naltrexone Pigeon Narcotic antagonism Intracerebroventricular

SEVERAL strategies have been used for examining the importance of central and peripheral mechanisms of pharmacological effects in vivo. A marked difference in the potency of a compound when administered centrally and peripherally can indicate the relative importance of central and peripheral mechanisms. In rats, for example, the analgesic $[3,13,14]$, discriminative $[6,18]$, rate-suppressant $[2]$, and locomotor-increasing [1] effects of opioid agonists (e.g., morphine) occur with much smaller doses when these drugs are administered directly into the central nervous system (CNS) as compared to the doses needed to induce these effects after systemic administration. Thus, these effects of opioids are mediated predominantly by central mechanisms.

Comparisons of the behavioral effects of systemicallyadministered tertiary and quaternary derivatives of drugs have also been used as indices of central and peripheral mechanism. Quaternization of the opioid antagonist naltrexone, for example, does not markedly affect its ability to displace $\left[{ }^{3} \mathrm{H}\right]$ etorphine from rat brain membranes or its ability to antagonize morphine's inhibitory effects on the guinea pig ileum [19]. However, in most, but not all $[5,12,17]$ in ivo experiments neither quaternary opioid antagonists [5, $16,19]$ nor quaternary opioid agonists [11] mimic the actions of their respective tertiary forms when administered systemically. Given the similar spectrum of action of quaternary and tertiary naltrexone in vitro, and the marked differences in the effects of these compounds when administered systemically in vivo, it is generally assumed, for example, that the lack of activity displayed by quaternary antagonists in vivo is a direct result of their inability to enter the CNS [4].

These data have provided presumptive, although not conclusive, evidence that the mechanisms responsible for many of the actions of opioid agonists and antagonists are located within the CNS. More direct evidence can be obtained from procedures which examine the effects of tertiary and quaternary derivatives when given by various routes of administration (e.g., [5,9]). To date, most experimental procedures which involve the administration of drugs directly into the CNS are of short duration, and cannula placement can only be determined with histological techniques upon termination of the experiment. The present study illustrates the long-term use of a cannula system in pigeons and the usefulness of a non-invasive radiographic verification procedure; relatively little is known about the pharmacological and behavioral significance of the blood-brain barrier (BBB) in the pigeon, despite the extensive use of this species within behavioral pharmacology. In addition, some results are described for compounds presumed to have different capacities for entering the CNS. The rate-suppressing effects of intracerebroventricular (ICV) and intramuscular (IM) morphine, naltrexone (tertiary), and naltrexone methobromide (quaternary naltrexone) were examined, as well as the effectiveness of ICV and IM naltrexone and quaternary naltrexone in antagonizing the rate-suppressing effects of IM morphine.

'Supported by USPHS Grant DA 00154. Portions of these data were presented at the 92nd Annual Convention of the American Psychological Association, Toronto, August, 1984 [8].

"Requests for reprints should be addressed to Charles P. France, Department of Pharmacology, 6322 Medical Science Building I, University of Michigan Medical School, Ann Arbor, MI 48109-0010. 
METHOD

Subjects

White Carneaux pigeons (Palmetto, Sumter, SC) weighing $401-770 \mathrm{~g}$ were reduced to $80 \%$ of their free-feeding weight. The reduced body weight was maintained by food earned during experimental sessions and supplemental feeding in the home cage (mixed grain and Purina Pigeon Checkers) where water and grit were freely available. Twenty-six pigeons have been cannulated to date for various experiments; the data in the present study were obtained with eleven pigeons.

\section{Apparatus}

Experimental sessions were conducted in a ventilated, sound-attenuated operant chamber measuring $36 \mathrm{~cm}$ high $\times$ $28 \mathrm{~cm}$ wide $\times 33 \mathrm{~cm}$ long. Three translucent response keys $(2.4 \mathrm{~cm}$ diameter) were located on the inside of one wall, approximately $25 \mathrm{~cm}$ from the chamber floor. During periods of food availability, the center key was transilluminated green by a $7-W$ light located behind the key. Reinforcement consisted of a 4-sec access to mixed grain, made available via a hopper that pivoted into an opening in the wall, directly below the response key. During reinforcement the key light was off and a white light illuminated the hopper. A Texas Instruments $960 \mathrm{~A}$ computer (Texas Instrument, Inc., Dallas, TX) and cumulative response recorders (Ralph Gerbrands Co., Arlington, MA), located in an adjacent room, were used for control of experimental events, data collection, and recording.

\section{Surgery}

Pigeons were anaesthetized with $2.5 \mathrm{ml} / \mathrm{kg}$ Chloropent (chloral hydrate and pentobarbital (Fort Dodge Laboratories, Inc., Fort Dodge, IA)) and $5.0 \mathrm{mg} / \mathrm{kg}$ ketamine, and a chronic, indwelling guide cannula $(8.5 \mathrm{~mm}$ in length, $22 \mathrm{~g}$ stainless steel (Plastic Products, Inc.)) was surgically implanted using stereotaxic procedures and a Revzin adaptor [15]. An attempt was made to place the tip of the guide cannula directly into the lateral ventricle using the coordinates: $8.8 \mathrm{~mm}$ dorsal and $6.8 \mathrm{~mm}$ rostral from the interaural axis, and $1.5 \mathrm{~mm}$ lateral from the midline (Fig. 1). The cannula was permanently fixed with skull screws and Cranioplastic.

Following surgery, and once every month thereafter, each bird was anaesthetized with $25.0 \mathrm{mg} / \mathrm{kg}$ ketamine and cannula patency was assessed by radiographs taken immediately after an ICV injection of 10-20 $\mu$ l (6-12 mg) radio-opaque dye (Conray (Mallinckrodt, Inc., St. Louis, MO)). A 28 g dummy cannula (Plastic Products, Inc.) was inserted into the guide cannula, except during infusions.

\section{Procedure}

Pigeons were trained to respond on a single key by differential food reinforcement of successive approximations of the key peck. Experimental sessions were conducted on three consecutive days each week, and consisted of five discrete 15 minute trials. Each trial consisted of a ten minute pretreatment period, during which the chamber was dark and key pecks had no programmed consequence, and a five minute response period, during which reinforcement was available on a variable-interval 30 second (VI30') schedule of food delivery (i.e., the first response, after an average inter-

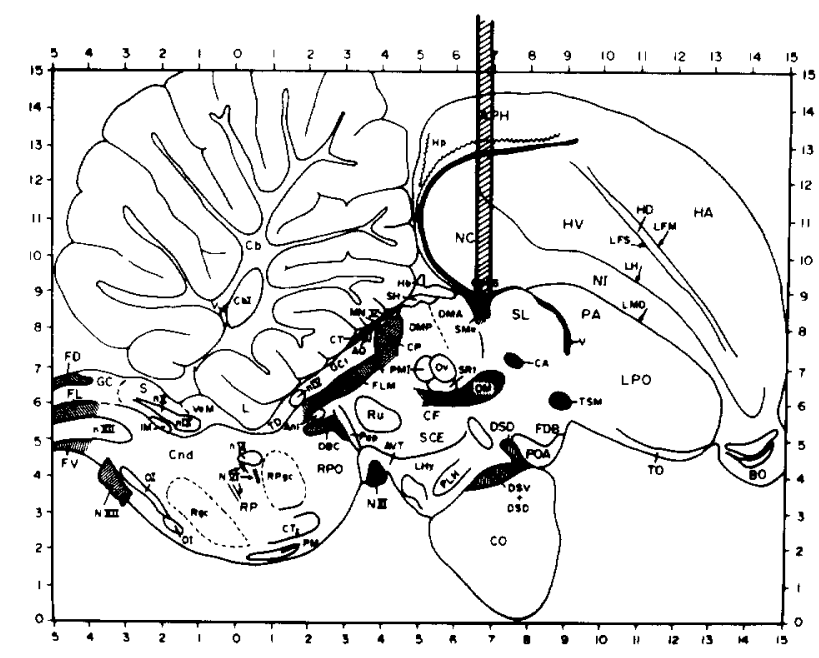

FIG. 1. A schematic lateral view (sagittal, $1.0 \mathrm{~mm}$ from midline) of the pigeon brain showing the cannula tract (hatched) and lateral ventricle (shaded). (Reproduced with permission from Karten and Hodos. 1967, p. 176.)

val of 30 seconds since the previous food delivery, was reinforced). Prior to each control (i.e., non-test) session, pigeons received an injection of saline $(1 \mathrm{ml} / \mathrm{kg}$. IM) or sterile water $(10 \mu \mathrm{l}, \mathrm{ICV})$.

\section{Testing}

Tests were conducted once per week, and drug injections were given one hour, ten minutes, or immediately before the beginning of the test session (see Results section). Systemic injections were made to the breast muscle in a volume of 1 $\mathrm{ml} / \mathrm{kg}$ body weight. Central injections (injection volume 10 $\mu \mathrm{l})$ were performed manually over a period of one to two minutes with a $100 \mu \mathrm{l}$ Hamilton syringe connected to a $28 \mathrm{~g}$ injection cannula (Plastic Products, Inc.) with PE 20 polyethylene tubing. The injection cannula was held in place for an additional one to two minutes in order to reduce the possibility of fluid backflow through the guide cannula. The injection cannula protruded $0.5 \mathrm{~mm}$ beyond the tip of the guide cannula. The order of tests for individual subjects was non-systematic.

In order to determine the rate-suppressing effects of each compound, a single injection (ICV or IM) of morphine, naltrexone, or naltrexone methobromide was administered immediately before the first of five test trials. This multiple-trial procedure allowed for evaluation of the time course of ratesuppressing effects over a $1 \frac{1 / 4}{\mathrm{hr}}$ session. For tests of antagonism, a single injection (ICV or IM) of naltrexone or naltrexone methobromide was administered ten or 60 minutes prior to the beginning of the first test trial. Additionally, a dose of $10.0 \mathrm{mg} / \mathrm{kg}$ morphine (IM) was administered immediately before the first trial. The data are expressed as the mean percentage of the vehicle (control) response rate \pm 1 S.E.M., for four pigeons at each drug condition.

\section{Drugs}

The drugs used in this experiment were morphine sulfate (Mallinckrodt, Inc., St. Louis, MO), naltrexone hydrochloride (Endo Laboratories, Inc., Garden City, NY) and nal- 


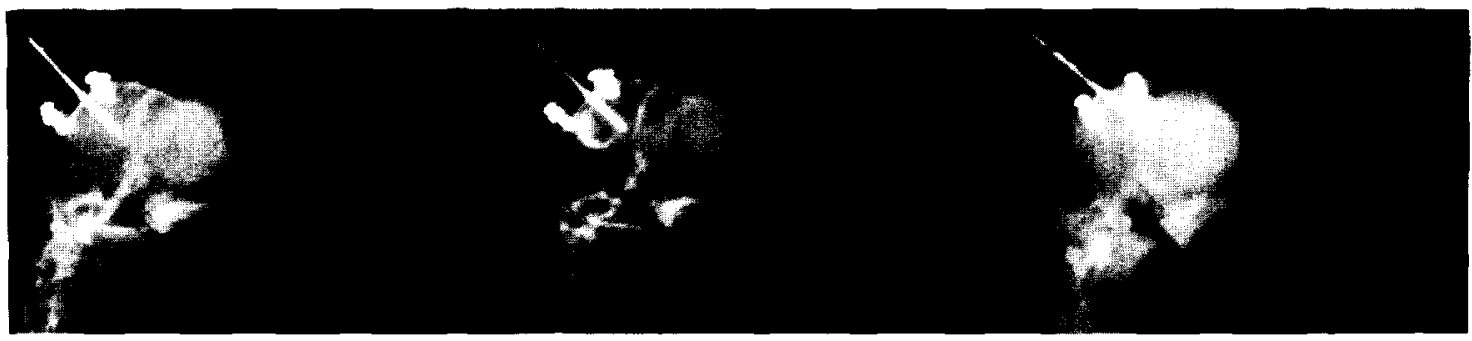

FIG. 2. Radiographs taken prior to (left panel) or immediately after (center and right panels) an ICV injection of 10-20 $\mu \mathrm{l}$ radio-opaque dye. The pigeons shown in the center and right panels were judged to have a positive and a negative cannula placement, respectively.

MORPHINE

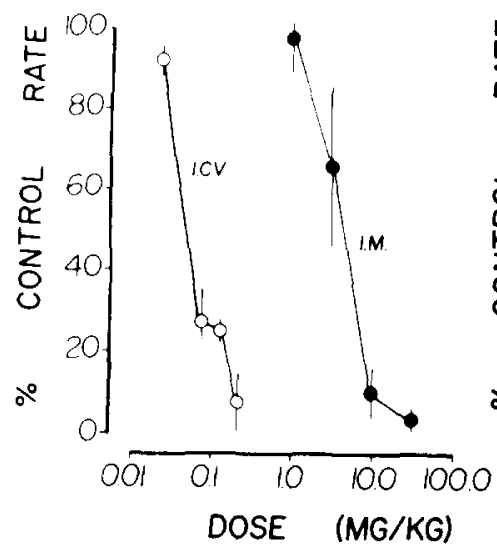

NALTREXONE

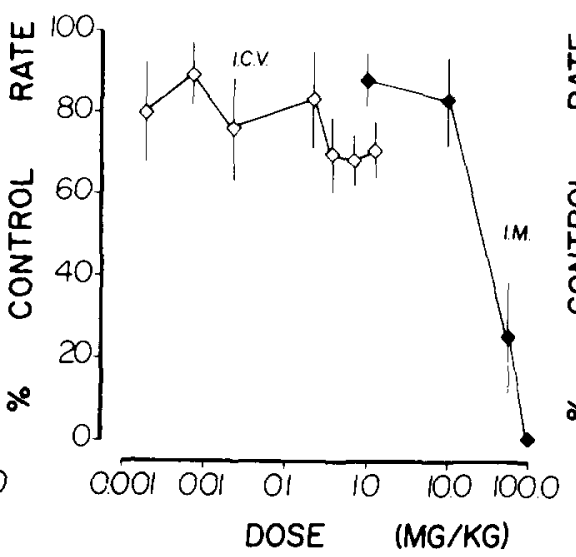

\section{QUATERNARY} NALTREXONE

FIG. 3. Dose-effect curves for the rate-suppressing effects of ICV (open symbols) and IM (closed symbols) morphine (left panel), tertiary naltrexone (middle panel), and quaternary naltrexone (right panel). Injections were made ten minutes prior to the first of five test trials, and each point represents the mean \pm 1 S.E.M. of four pigeons, for all five trials. Ordinate: mean response rate, expressed as a percentage of the saline control rate. Abscissae: dose in milligrams per kilogram body weight. Fixed doses were administered ICV (e.g.. $100 \mu \mathrm{g}$ ), however for display purposes the fixed doses have been converted to mg/kg.

trexone methobromide (MRZ 2663BR, Dr. H. Merz, C. H. Boehringer Sohn, Ingelheim am Rhein. Federal Republic of Germany). Morphine and naltrexone were dissolved in sterile $0.9 \%$ saline for systemic administration, and in sterile water for central administration. Naltrexone methobromide was dissolved in sterile water.

\section{RESULTS}

\section{Cannula Verification}

Cannula placement was determined by $\mathrm{x}$-rays in which the distribution of radio-opaque dye delineated the ventricuIar horn. Cannula placement was judged to be negative if the dye appeared to diffuse to areas other than the ventricular space or, more typically, if dye was concentrated only at the cannula tip (Fig. 2, right panel). Of 26 surgical attempts to date, $19(73 \%)$ have resulted in successful placement of the guide cannula tip into the lateral ventricle, as determined by diffusion of the dye throughout the lateral ventricle (Fig. 2, center panel). Of 19 subjects judged initially to have positive cannula placement, four died from causes unrelated to cannulation, two lost their cannula within five months of surgery (apparently a result of the cannula being bumped or caught in the home cage), four were subsequently judged negative after $10.4 \pm 3.2$ months (range $=2.0-17.5$ ), and nine pigeons are still positive after $9.7 \pm 1.1$ months (range=4.1-17.0). Only data obtained from experiments which were both preceded and followed by a positive $x$-ray were included in the analysis.

Rate-Suppressing Effects of Morphine, Naltrexone, and Quaternary Naltrexone

Morphine dose-dependently suppressed food-reinforced responding when administered ICV or IM. A dose of 10.0 or $32.0 \mathrm{mg} / \mathrm{kg}$ morphine IM suppressed responding to a mean rate of less than $10 \%$ of the saline control rate over the five trial session, while a dose of $100.0 \mu \mathrm{g}(0.21 \mathrm{mg} / \mathrm{kg}) \mathrm{ICV}$ was required to produce a comparable suppression of rates (Fig. 3 ). Thus, morphine was 50-150 times more potent in suppressing behavior when administered ICV.

Quaternary naltrexone also suppressed responding by both routes of administration. Systemically, $100.0 \mathrm{mg} / \mathrm{kg}$ was the smallest dose of quaternary naltrexone that reliably suppressed response rates to less than $10 \%$ of the control rate (Fig. 3). Administration of $100.0 \mu \mathrm{g}(0.206 \mathrm{mg} / \mathrm{kg})$ quaternary 


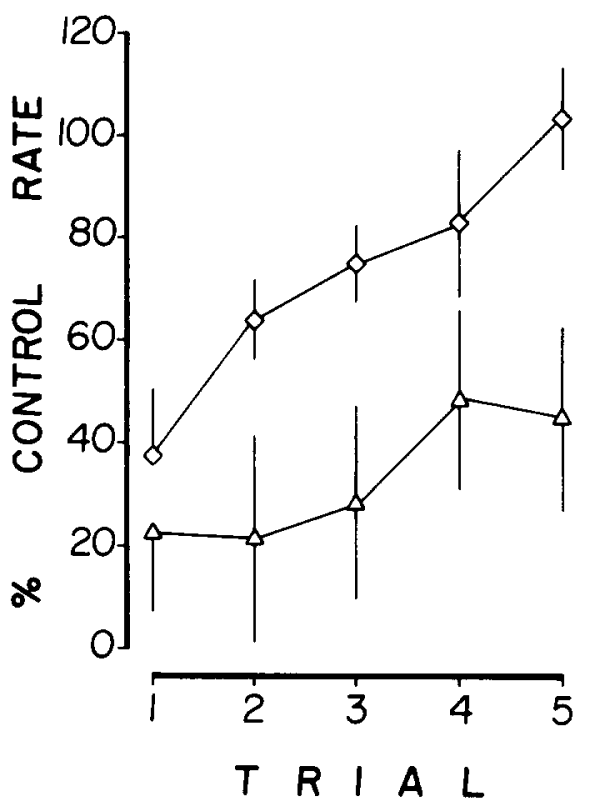

FIG. 4. The rate-suppressing effects of a single ICV injection of $320.0 \mu \mathrm{g}$ tertiary (diamonds) or $56.0 \mu \mathrm{g}$ quaternary (triangles) naltrexone over a five trial $(11 / 4 \mathrm{hr})$ test session. Abscissa: successive 15 minute trials. Other information as in Fig. 3.

naltrexone ICV suppressed responding completely over the $1 \frac{1 / 4}{4}$ hour test session and was accompanied by violent shaking and vomiting.

Tertiary naltrexone (IM) also suppressed responding dose-dependently, and was equipotent to systemicallyadministered quaternary naltrexone (Fig. 3). Although the largest ICV dose of tertiary naltrexone that has been evaluated, $560.0 \mu \mathrm{g}(1.22 \mathrm{mg} / \mathrm{kg})$, suppressed responding partially in all animals, the mean response rate for the five trial session was greater than $50 \%$ of the vehicle control rate. Higher doses could not be tested because doses of tertiary naltrexone greater than $100.0 \mu \mathrm{g}$ also induced pronounced, although comparatively short-lived, shaking and vomiting.

The failure of tertiary naltrexone to suppress responding completely appeared to be related to the time course of its effects. Figure 4 shows the time course for a single ICV injection of $320.0 \mu \mathrm{g}$ tertiary naltrexone or $56.0 \mu \mathrm{g}$ quaternary naltrexone. While these doses produced a similar degree of rate suppression during the first trial $(20-40 \%$ of control rates), the effects of tertiary naltrexone dissipated very rapidly such that responding had recovered completely by the fifth trial. Quaternary naltrexone, however, continued to suppress rates for the duration of the $1 \frac{1 / 4}{\mathrm{hr}}$ test session. Larger doses of quaternary naltrexone (i.e., $100.0 \mu \mathrm{g}$ ) which suppressed responding completely on the day of administration, also suppressed rates $24 \mathrm{hr}$ later to $41.5 \pm 13.4 \%$ of the control rate. There were no apparent rate effects $24 \mathrm{hr}$ after ICV or IM tertiary naltrexone, or $24 \mathrm{hr}$ after IM quaternary naltrexone.

\section{Antagonism of Morphine's Rate-Suppressing Effects}

The potency of tertiary naltrexone in antagonizing the rate-suppressing effects of $10.0 \mathrm{mg} / \mathrm{kg}$ morphine IM was approximately the same by the two routes of administration (Fig. 5). The smallest doses of tertiary naltrexone that effec-

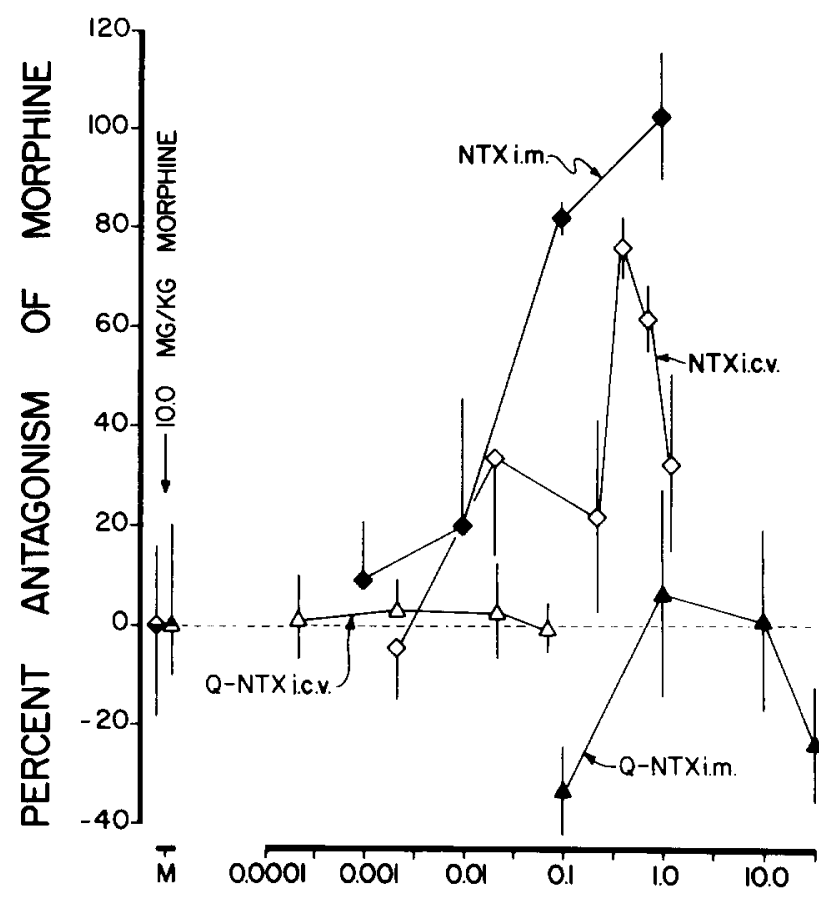

ANTAGONIST DOSE (MG/KG)

FIG. 5. Dose-effect curves for ICV and IM tertiary and quaternary naltrexone administered prior to $10.0 \mathrm{mg} / \mathrm{kg}$ morphine (IM): closed diamonds, IM tertiary naltrexone; open diamonds, ICV tertiary naltrexone; closed triangles. IM quaternary naltrexone; open triangles. ICV quaternary naltrexone. All antagonist pretreatments were given ten minutes prior to morphine, except ICV quaternary naltrexone which was administered 60 minutes prior to morphine. The leftmost points represent the effects of $10.0 \mathrm{mg} / \mathrm{kg}$ morphine administered alone; the symbol on the left corresponds to the animals shown with the same symbol on the right. Ordinate: antagonism of morphine. expressed as a percent increase of morphine's suppressing effects $(0 \%=$ effects of morphine alone $(67-91 \%$ suppression of control rate); $100 \%=$ saline control rate). Abscissa: pretreatment dose of antagonist $(\mathrm{mg} / \mathrm{kg})$. Other information as in Fig. 3.

tively antagonized morphine were $0.1 \mathrm{mg} / \mathrm{kg} \mathrm{IM}$ and 0.389 $\mathrm{mg} / \mathrm{kg}(180.0 \mu \mathrm{g}) \mathrm{ICV}$. A dose of $1.0 \mathrm{mg} / \mathrm{kg} \mathrm{IM}$ antagonized completely the suppressing effects of $10.0 \mathrm{mg} / \mathrm{kg}$ morphine, whereas doses greater than $180.0 \mu \mathrm{g}$ tertiary naltrexone ICV did not produce additional antagonism.

Up to a dose of $32.0 \mathrm{mg} / \mathrm{kg}$ IM or $0.069 \mathrm{mg} / \mathrm{kg} \mathrm{ICV} 32.0$ $\mu \mathrm{g})$, quaternary naltrexone failed to antagonize the ratesuppressing effects of $10.0 \mathrm{mg} / \mathrm{kg}$ morphine IM (Fig. 5). Larger doses were not evaluated because they suppressed response rates to less than $30 \%$ of the control rate when administered alone (Fig. 3).

\section{DISCUSSION}

The radiographic procedure used in this study for the periodic assessment of cannula patency allows for the incorporation of ICV drug administration in long-term behavioral experiments. Although there is a report on the use of this radiographic procedure for evaluating cannula patency in primates [10], cannula placement is most often assessed post hoc by histological techniques. These techniques, however, have the disadvantage of not permitting one to determine the cannula location until the experiment has been completed, 
and are, therefore, inappropriate for long-term behavioral experiments. In the absence of reliable in vivo procedures for assessing ICV cannula patency, significant time and energy could potentially be invested in animals with improper cannula placement.

It has been suggested for the pigeon that leakage of cerebrospinal fluid (CSF) when the dummy cannula is removed indicates proper placement of the cannula into the ventricle [7]. Use of this criterion alone, however, may result in a significant number of false-negative judgements of cannula patency. Leakage of CSF was observed periodically in the present study, but unambiguous positive $x$-rays were obtained with pigeons that never leaked CSF. The results obtained in 26 cannulated pigeons do not show a clear relationship between positive cannula placement and leakage of CSF. Although placement of the cannula tip into the lateral ventricle may not be important for all experiments (e.g., when lipophilic compounds which pass readily throughout the CNS are administered), there are undoubtedly situations in which the exact location of the cannula will influence the results that are obtained (e.g., hydrophilic, highly charged molecules which will, presumably, not diffuse readily throughout the CNS).

It has previously been shown that systemicallyadministered quaternary naltrexone fails to mimic the actions of tertiary naltrexone in the pigeon. Quaternary naltrexone did, however, bind to opioid recognition sites and attenuate the effects of morphine in vitro [19]. The presumed profile of action of quaternary derivatives has, therefore, established them as ideal pharmacological probes for differentiating central and peripheral effects. In agreement with earlier reports [19] IM quaternary naltrexone was not an effective antagonist of morphine's behavioral effects in the pigeon. Furthermore, despite its well-documented antagonist actions in vitro, albeit with 50-fold less affinity than tertiary naltrexone, ICV quaternary naltrexone did not antagonize the rate-suppressing effects of morphine. These data indicate, based upon the relative affinities of tertiary and quaternary naltrexone in vitro [19], that doses of quaternary naltrexone which one would predict to be effective against morphine if the BBB is circumvented, exert rate-suppressing effects when administered ICV. The relative ability of tertiary and quaternary naltrexone to diffuse from the ventricle through brain tissue to opioid receptors also may have contributed to the differences observed in their abilities to antagonize morphine. Quaternization of naltrexone may prevent it from readily passing through brain tissue and, thus, ICV quaternary naltrexone may only antagonize actions of morphine that are mediated periventricularly. The direct effects of quaternary naltrexone in suppressing responding, however, appeared to prevent it from antagonizing morphine under these experimental conditions.

It has been suggested that the effectiveness of other opioid antagonists may also be limited by their direct effects on behavior [20]. Furthermore, it has been shown that ICV quaternary naltrexone is an effective morphine antagonist in the rat $[5,9]$, however neither of these studies employed rate of responding as a behavioral measure. Quaternary naltrexone might also antagonize some effects of morphine in the pigeon if a measure other than rate of responding were used. The ideal compound for differentiating central and peripheral effects may be one which is unable to pass the BBB, but has the same affinity as the tertiary form for opiate recognition sites.
The results obtained in the present study were in agreement with previous reports $[9,18]$ which indicated that lipophilic opioid antagonists (i.e., naloxone and naltrexone) are approximately equipotent when administered ICV or systemically because they diffuse easily across the BBB. Naltrexone had a similar antagonist potency whether injected centrally or peripherally, and was little if any more potent in suppressing food-maintained responding when administered ICV. Furthermore, the rapid offset of naltrexone's rate-suppressing effects when administered ICV indicate that it diffuses quickly out of the pigeon brain. This result contrasts with the long duration of rate suppression produced by large doses of quaternary naltrexone, presumably due to its inability to pass from the CNS to the periphery. It is believed that the rate-suppressing effects of opioid antagonists in non-dependent animals are not due to actions on opioid receptors, although relatively little is known regarding the mechanism of action of antagonists in non-dependent animals. The procedure described herein may be particularly useful for comparing the mechanism(s) of action for the direct (i.e., rate-suppressing) effects of opioid antagonists in the CNS and periphery.

Potency differences of 2-300 fold have been demonstrated for various effects produced by morphine when it is administered centrally or peripherally in rats $[2,3,18]$ and monkeys (Gmerek, personal communication). Based upon potency relationships for morphine given by different routes of administration, it has been argued that the ratesuppressing effects of morphine in the rat are predominantly due to its effects on CNS opioid mechanisms [1]. Morphine may also suppress food-reinforced responding in the pigeon by central mechanisms, given that it was approximately 100 times more potent in suppressing responding when administered ICV There may also be a peripheral component to morphine's rate-suppressing effects, given that tertiary naltrexone was slightly more potent as an antagonist when administered systemically. However, the lack of antagonism observed with systemically-administered quaternary naltrexone argues against this possibility. The rate-suppressing effects of centrally-administered quaternary naltrexone precluded an evaluation of possible antagonistic effects at larger doses, whereas systemically-administered quaternary naltrexone was evaluated up to doses which one would predict, based upon the relative potencies of tertiary and quaternary naltrexone in vitro [19], to be effective in attenuating the actions of morphine.

The cannula verification procedure reported herein has been used successfully in our laboratory for periodically assessing cannula patency in both pigeons and monkeys [10], and could likely be adapted for other species. This procedure may significantly contribute to behavioral pharmacology given the extensive use of the pigeon in drug studies and the paucity of reliable in wiv cannula verification techniques. Although $73 \%$ of the cannulations were initially judged positive, due to various factors, only $47 \%$ (9 of 19) of those animals were still positive after ten months of experimentation. Additional experience in our laboratory with this procedure now indicates that the success rate and longevity of ICV cannulae in pigeons has improved considerably. $\mathrm{Fi}$ nally, the failure of quaternary naltrexone to antagonize the effects of morphine suggests that the typical approach of comparing systemically-administered tertiary and quaternary naltrexone may not provide sufficient evidence for implicating central mediation of a particular behavioral effect. 


\section{REFERENCES}

1. Brady, L. S. and S. G. Holtzman. Effects of intraventricular morphine and enkephalins on locomotor activity in nondependent, morphine-dependent and postdependent rats. $J$ Pharmacol Exp Ther 218: 613-620, 1981.

2. Brady, L. S. and S. G. Holtzman. Effects of intraventricular morphine and enkephalins on schedule-controlled behavior in nondependent, morphine-dependent and postdependent rats. $J$ Pharmacol Exp Ther 219: 344-352, 1981.

3. Brady, L. S. and S. G. Holtzman. Analgesic effects of intraventricular morphine and enkephalins in nondependent and morphine-dependent rats. J Pharmacol Exp Ther 222: 190-197, 1982.

4. Brown, D. R. and S. G. Holtzman. Opiate antagonists: central sites of action in suppressing water intake in the rat. Brain Ro's 221: 432-436, 1981

5. Brown, D. R., M. J. Robertson and L. I. Goldberg. Reversal of morphine-induced catalepsy in the rat by narcotic antagonists and their quaternary derivatives. Neuropharmacology 22: 317$321,1983$.

6. Colpaert, F. C., C. J. E. Niemegeers, P. A. J. Janssen and J. M. Van Ree. Narcotic cueing properties of intraventricularly administered sufentanil, fentanyl, morphine and met-enkephalin. Eur J Pharmacol 47: 115-119, 1978.

7. Deviche, P. and G. Schepers. Intracerebroventricular injection of ostrich $\beta$-endorphin to satiated pigeons induces hyperphagia but not hyperdipsia. Peptides 5: 691-694, 1984.

8. France, C. P. Intracerebroventricular morphine, naltrexone and quaternary naltrexone in the pigeon. Pharmacol Biochem Bsha' 20: 991,1984

9. Gmerek, D. E., A. Cowan and J. H. Woods. Independent central and peripheral mediation of morphine-induced inhibition of gastrointestinal transit in rats. I Pharmacol Exp Ther, in press.

10. Gmerek, D. E., J. L. Katz, C. P. France and J. H. Woods. Systemic and intracerebroventricular effects of opioid peptides in withdrawn morphine-dependent rhesus monkeys. Lif $f^{\prime} S_{c^{\prime}} i \mathrm{B3}$ : $361-364,1983$
11. Hein, D. W., A. M. Young, S. Herling and J. H. Woods. Pharmacological analysis of the discriminative stimulus characteristics of ethylketazocine in the rhesus monkey. J Pharmacol Exp Ther 218: 7-15, 1981.

12. Hemmer, R. C., G. A. Olson, A. J. Kastin, J. H. McLean and R. D. Olson. Effects of naloxone and its quaternary form on fluid consumption in rats. Pharmacol Bioche'm Bcha' 17: 1287-1290, 1982.

13. Herz, A. and H. J. Teschemacher. Activities and sites of antinociceptive action on morphine-like analgesics and kinetics of distribution following intravenous, intracerebral and intraventricular application. Adv Drug Res 6: 79-119. 1971.

14. Herz, A. and H. J. Teschemacher. Direct application of narcotics into the brain. In: Factors Affecting the Action of Narcotic's edited by M. L. Adler, L. Manara and R. Samanin. New York: Raven Press, 1978, pp. 161-172.

15. Karten, H. J. and W. Hodos. A Sterestaxic Atlas of the Brain of the Pigeon (Columba livia). Baltimore: John Hopkins Press. 1967

16. Koob. G. F., H. O. Petit, A. Ettenberg and F. F. Bloom. Effects of opiate antagonists and their quaternary derivatives on heroin self-administration in the rat. I Pharmacrsl Exp Ther 229: 481-486, 1984.

17. Russell, J., P. Bass, L. I. Goldberg, C. R. Schuster and H. Merz. Antagonism of gut. but not central effects of morphine with quaternary narcotic antagonists. Eur I Pharmacol 78 : $255-261,1982$.

18. Shannon, H. E. and S. G. Holtzman. Discriminative effects of

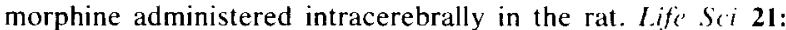
585-594, 1977.

19. Valentino, R. J., S. Herling, J. H. Woods, F. Medzihradsky and H. Merz. Quaternary naltrexone: evidence for the central mediation of discriminative stimulus effects of narcotic agonists and antagonists. J Pharmacol Exp Ther 217: 652-659. 1981

20. Young, A. M. and J. H. Woods. Limitations of the antagonistic actions of opioid antagonists. Fed Prec 41: 2333-2338. 1981. 